\title{
Effective National Innovation Ecosystems as a Framework for Business Models Innovations
}

\author{
Jan Stejskal, Petr Hajek, Michaela Kotkova Striteska, Viktor Prokop \\ University of Pardubice, Faculty of Economics and Administration, Czech Republic
}

\begin{abstract}
Support of establishment and functioning of National Innovation Ecosystems (NIEs) is a way how to influence innovation performance and business models innovation at national level. It could be understood as a synergistic tool for implementing a triple- (and/or quadruple-) helix principles in practice. It is due to the fact that effective functioning NIEs enable a connection of different agents (actors) from various sectors. Namely, these are private stakeholders, public sector authorities (regardless of the level of governance), as well as the society or various communities. These NIEs can be observed at all levels of business activity, from global, through national, to regional and local. Therefore, over the last two decades, politicians have sought to create so called innovation system in each region, with the help of policy instruments and public funding from national and EU funds. This tool aimed to create a stable environment suitable for the emergence of innovations, their acceleration, reduction, respectively. Synergistic effects of national systems (NIEs) were expected (e.g. in the emergence of new knowledge, the start of cooperation, spread of technologies, building of social capital). Similarly, spillover effects were expected to other regions and other economies of the globalized business environment. However, not all expectations have been fulfilled and it is possible to talk about the inefficiency of public but also private support for building NIEs. Therefore, we aim to measure efficiency of NIEs functioning by using Data Envelopment Analysis (DEA) and its modifications. For this purpose, we are using data about 32 OECD countries. The results of this study help us to identify ways to achieve more effective outputs from innovation cooperation and knowledge creation within various NIEs. Moreover, based on these results, we propose country-specific changes in the treatment of individual sources of innovation processes in order to achieve more efficient outputs in the future. Such effective NIEs will enable the creation of an environment for effective innovation of business models with regard to specific conditions in different OECD countries.
\end{abstract}

Keywords: National Innovation Ecosystems; Business Models Innovations; Cooperation; DEA 